\title{
The Design and Application of Hospital Personnel Salary and Performance System
}

\author{
Qianying Gao, Yulin Deng \\ Business School of Hohai University, Nanjing Jiangsu, China, 211100
}

Keywords: Hospital; personnel salary; performance; system

\begin{abstract}
In order to meet the needs of work development and medical reform, the research and development of hospital performance management system has become one of the hot spots of hospital information management in China. It is of great significance to design and implement a complete, feasible, functional and easy-to-operate performance appraisal management system for mobilizing the enthusiasm, initiative and creativity of the staff in the hospital, forming a situation of winning by quality and giving priority to performance, improving the service level of the hospital and enhancing the core competitiveness. Therefore, the design and development of hospital performance management system is very necessary.
\end{abstract}

\section{Introduction}

The research shows that there are four main modes of performance wage management in large and medium-sized hospitals in China, namely, revenue and expenditure balance Commission mode, doctor fee commission mode, budget management mode, total amount Commission mode. Generally speaking, the balance of payments model and the doctor fee commission model are too simple to consider the quality of medical care, patient satisfaction, waiting time and other factors. It seems simple and practical operation is very difficult. The budget management mode and the total amount withdrawal mode can be linked with the comprehensive performance of the whole hospital, departments and individuals (including workload, service quality and various financial indicators) [1], linked with the post establishment, and can be allocated to people one by one, seemingly complex. Under the condition of information system, automatic accounting and distribution can be realized, which is the first choice of large and medium-sized hospitals.

\section{The goal of hospital performance management system construction.}

\subsection{Ensuring fairness}

"Do not suffer from widows but are not evenly distributed." It is the general mentality of hospital staff. Hospital performance appraisal is a double-edged sword, if the appraisal mechanism is fair, it will greatly stimulate the enthusiasm and initiative of medical staff; otherwise, if it is not fair, it will hamper the enthusiasm of medical staff, not conducive to medical staff to do a good job of quality and quantity. I believe any leader of a hospital would not like to see this happen later. Therefore, we 
should equate the assessment mechanism to the primary objective of implementing the hospital performance appraisal system.

\subsection{Enhance efficiency}

Management is productivity." Hospital performance appraisal system as an important means of hospital management is to help hospitals to enhance medical productivity, to create higher social and economic benefits for the hospital. Social benefit indicators include the number of patients (including outpatients and inpatients), drug use indicators, patient burden and other indicators. Economic benefits include business income, balance of payments, net profit and other indicators. Only when the application of the hospital performance appraisal system promotes the positive promotion of the social and economic benefits of the hospital, can we believe that the benefit goal has been achieved.

\subsection{Improve efficiency}

Hospital performance appraisal is a time-consuming and laborious work. The application of performance appraisal system should greatly improve the efficiency of hospital performance appraisal and release a large number of high-end human resources energy. Specifically speaking, it is necessary to liberate department directors and head nurses from the data registration, data collection, performance wage accounting, performance wage communication and other work in department performance appraisal, and return the effective working hours of department directors and head nurses to doctors, nurses and patients so that they no longer need to assign work exercises to department performance. The human resources department or performance office staff from the cumbersome data collection, data accounting, so that they do more valuable performance management work.

\subsection{Maintain balance}

The so-called balance means achieving the balance between long-term development goals and short-term development goals. In order to achieve the goal of balancing the hospital performance appraisal system, two aspects of work should be done well: first, the long-term development goals and key action plans in the hospital strategic planning should be incorporated into the hospital performance appraisal system to manage; secondly, the teaching and scientific research work of hospitals and departments should be included in the daily appraisal work, so as to be able to. Promote balanced development of hospitals and departments.

\subsection{Effective incentives}

Hospital performance appraisal system should create benefits for hospitals, so the performance appraisal system must be motivated. "Without satisfactory medical staff, there will be no satisfactory patients." Front-line health care workers are directly productive jobs, and if they are not motivated to cope passively with the work, then patients may not be able to expect the medical services. The incentive of the hospital performance appraisal system has two elements: on the one hand, the amount of performance salary must be attractive to the medical staff; on the other hand, the standard of performance salary must be maintained at least at the average level of the industry market; on the other hand, if the staff want to get more incentives, it is feasible through their personal efforts. Achieved. 


\section{Hospital personnel pay and performance system}

Macroscopically speaking, hospital performance management refers to the operating performance of a hospital during a certain period of operation, reflecting the process, results and the ability to achieve the desired objectives of the hospital in various activities, the same activities can be reflected in departments and individuals, in order to achieve fine management, performance management in accordance with different posts. All employees perform performance management.

On the basis of the previous investigation and the successful examples of other hospitals, through the data mining and utilization of human resource management system, clinical business management system and medical quality management system, the balanced scorecard is used as the method of performance management. Before the performance management system of balanced scorecard is constructed, the balanced scorecard is used as the balanced scorecard. In order to establish and implement the card, the mission and strategy of the hospital should be transformed into management objectives and evaluation methods, and the performance evaluation indicators of different departments, posts and personnel should be summarized and classified, including service ability, technical level, diagnosis and treatment behavior, work efficiency, economic benefits, patient response, and doctors. Medical ethics, scientific research ability, teaching ability, basic links and final quality will be selected as the subjects of performance management system, and key performance indicators will be selected as the evaluation data and information source of the balanced scorecard. In selecting KPI [2-6], a personal KPI was formulated based on the principles of goal-oriented, operable and end-to-end quality. Through in-depth discussion among the hospital quality management committee, quality control management committee and economic management committee, the weight of each index was given, and the posts were established according to the budgets of hospitals and departments at the beginning of the year. The Balanced Scorecard performance management system is shown in Table 1 .

Table 1 Hospital personnel remuneration and performance system structure

\begin{tabular}{|c|c|c|}
\hline Serial number & Project & System \\
\hline 1 & Financial & Cost accounting management system \\
\hline 2 & Patient & Satisfaction evaluation system \\
\hline 3 & Intelligent & $\begin{array}{c}\text { Management system for internal } \\
\text { process quality }\end{array}$ \\
\hline 4 & $\begin{array}{c}\text { Learning and } \\
\text { developing }\end{array}$ & Human resource management system \\
\hline
\end{tabular}

The data of financial indicators in each module of the Balanced Scorecard comes from the clinical business management platform, and the data of patient level comes from the clinical business management platform and the special patient satisfaction evaluation system (which can upload data directly and supervise directly by the higher health administration department), which has the strongest maneuverability. Data in the process module is shared directly from the data of the medical quality management platform, and there are more and more important indicators to be considered in the design of the terminal quality, so the proportion of the weights to be granted is also higher; the indicators of learning and growth level need to be extracted by intelligent human resource management system, such as in the trainer. Face, after accepting a continuing education assessment, give 5 points, give 10 points to the hospital, 5 points to the department, 10 points to the continuing education staff, 5 points to the intern, more than 90 points. This performance assessment is qualified, 95 points are good, 100 points are excellent. The policies formulated by hospitals give corresponding incentives. Before intelligent information management is realized, it needs a lot of manpower and material resources to complete these tasks, and can not guarantee its accuracy and 
objectivity.

\section{Establish a personnel remuneration system in line with the characteristics of the medical profession}

\subsection{Reform framework of personnel compensation system}

According to the reform ideas of public hospitals, we should sort out all the post systems of hospitals, reduce the merger of administrative levels, redefine posts, clarify post responsibilities, compile job descriptions, design scientific and reasonable performance indicators, establish key performance evaluation indicators of different levels, and be scientific, fair and public. Open assessment, improve and perfect the performance management system, establish an open and transparent performance evaluation system, adhere to the premise of public welfare, establish a quality and performance-oriented performance management system.

\subsection{Fixed posts, assigned and fixed responsibilities}

"Opinions" clearly pointed out that: within the total number of local existing establishment, the total number of public hospitals should be rationally approved, the establishment and management of public hospitals should be innovated, the establishment and filing system should be gradually implemented, and a dynamic adjustment mechanism should be established. Through the positioning of public hospitals, according to the analysis of the basic functions of hospitals, to determine the establishment of hospital posts, on-demand posts, through post analysis, adhere to the principle of streamlining and efficient to determine the rational allocation of posts, so as to achieve scientific posting, reasonable responsibility.

\subsection{Evaluation of department and post value}

The evaluation of department value and post value focuses on solving the problem of internal fairness of salary. First, it compares the relative importance of each department and post in the hospital, and obtains the rank sequence. Second, it makes the different positions comparable and lays the foundation for ensuring the fairness of post salary. It is the natural result of post analysis, and at the same time, it is based on the job description. It can provide important decision-making reference for making wage budget.

\subsection{Fixed salary and fixed salary}

On the basis of the "three definite" plan, the appointment system should be adopted. Under the guidance of the hospital management committee, the system of competition for appointment of the whole staff should be adopted to determine the candidate of the president. Competitive appointment system should be adopted for the responsible persons, and the staff should be optimized to set up a hospital personnel management system with appointment system as the main body.

\subsection{Workload efficiency integral method of performance management}

Workload efficiency, "four-dimensional drive" integration method, the connotation of performance management mode. In order to effectively solve the problem of unfair internal distribution, the performance wage system, which is dominated by income and expenditure balance, has been changed to the mode of performance appraisal and bonus distribution, which is based on workload accounting, focusing on quality and efficiency appraisal control and using comprehensive 
evaluation as a means. It has a positive and important role in promoting the return of public welfare in public hospitals.

Performance pay system that meets the needs of the medical profession. Because of the high pressure, high risk coefficient and labor intensity in the medical industry, the performance salary system should fully reflect the value of medical staff and the reward of their labor. With the increase of workload, the improvement of service attitude and the improvement of medical quality, the income of medical staff will be increased correspondingly, and the income of medical staff will be related to post responsibility, work performance and actual contribution. The operating mechanism of total wage fluctuating with hospital benefits and individual wage fluctuating with individual performance will be established. And promote the transformation of hospital performance management system.

The meaning of "four dimensional driving" of workload efficiency. In the actual hospital performance appraisal, this new performance management mode is embodied in workload-driven, cost control-driven, daily quality defect management efficiency appraisal-driven, key performance indicators performance appraisal-driven, and the construction of incentive mechanism and constraint mechanism pay equal attention to the "four-dimensional drive" management mode, in order to truly complete the hospital performance. Effective assessment management.

Workload-driven: mainly including the number of outpatient and emergency services, hospital beds, the number of various types of surgery, in order to make different hospitals, different types of services in the statistical assessment comparable, the use of standardized workload methods for statistical assessment.

Cost control drive: take the patient cost control as the breakthrough point, strengthen the control of variable cost on the premise that the patient cost can be controlled, strive to reduce the proportion of drugs and the ratio of health consumables, strengthen the level of fine management, improve the income level of medical service ability, and increase the income content.

Daily quality defect management effectiveness evaluation drive: main embodiment. Process management, professional management departments to effectively strengthen the daily process management, promote managers at the grass-roots level, strengthen meticulous management, timely discovery of defects and deficiencies, establish the management is the idea of service, rectify the management of supervision as a service of the wrong way of work, the implementation of incentives and deductions, careful use of the percentage system test Nuclear.

Efficiency evaluation drive of key performance indicators: mainly inclined to the results, combined with hospital strategic objectives, including medical quality, service efficiency, standardized diagnosis and treatment, rational use of drugs, reasonable control of fees, medical accidents, unit energy consumption, patient satisfaction and other aspects of comprehensive performance appraisal.

Performance wage accounting formula

Workload performance salary point $=$ performance salary total budget / workload total score

Department performance pay $=$ Department standardization workload $*$ standardization workload, performance pay point value

The formulas cover workload and its value, cost-benefit analysis, quality and satisfaction, and are constrained by the strategic objectives and operating objectives of the hospital. All the above-mentioned elements can be expanded and divided into many variables. Management economics has great significance and unlimited potential.

\section{Summary}

Feedback, learning and improvement of performance results are indispensable to the 
implementation of BSC performance management, one of the important links, but also the main purpose of BSC application. At the end of each execution cycle, it summarizes and analyzes, puts forward improvement suggestions to those who fail to meet the standards, supervises and implements them, and gives incentives to those who reach the standards, thus making the BSC performance management a dynamic, cyclic and continuous whole process. Regular feedback and learning can ensure the correct direction of hospital strategic objectives, dynamic changes in action objectives, and objective and effective performance indicators. After a period of operation, it has improved the enthusiasm of all staff, stimulated the creativity of staff, condensed the wisdom of all staff, so that all staff wholeheartedly into the construction and development of the hospital, to combine their own growth with the development of the hospital, giving full play to the strength of the hospital organizations and individuals. Quantity, give the best service to patients.

\section{References}

[1] Shan K E, Jin-Song M O, Yang B Z, et al. Designation and Application of Information System for Performance Appraisal of Ophthalmic Clinical Physicians Based on the RBRVS[J]. Medical Innovation of China, 2017.

[2] Tong D N, Wang D. Design and Implementation of File \& Salary Management System of Engaged Personnel in Military Hospital[J]. Chinese Medical Equipment Journal, 2011, 26(6):335-343.

[3] Xizhen H E, Li L I. The Practical Research on Hospital Performance Appraisal and Salary Management System[J]. China Health Standard Management, 2017.

[4] Aghaeinejad A A, Eshgh Z M, Peyman A, et al. Prevalence of Occupational Stressors from the Perspective of Pre-Hospital Personnel in Disaster and Emergency Medical Management Center[J]. Advances in Environmental Biology, 2014.

[5] Ma Y. Research on the Salary System Design of the Technical Personnel in State-owned Enterprises - Take Changqing Oilfield Exploration and Development Research Institute as an example[C]// International Conference on Innovations in Economic Management and Social Science. 2017.

[6] Carmelita S M. The consideration and evaluation of perquisites in determining the wage and salary scale of hospital staff members and personnel[J]. Hospital Progress, 1945, 26:388.

[7] Li X, Ltd A C. The Search on Production Personnel Performance Appraisal and Inspirit in Process of Organization Revolution of Enterprise__AIR CHINA Ltd as an Example [J]. Human Resources Development of China, 2013.

[8] Zhu C, Yang Q, Cai B. Design and Application of Human Resource Management Based on Office Automation System in Hospital[J]. China Digital Medicine, 2015.

[9] Mattarelli E, Fadel K J, Weisband S P. Design of a role-playing game to study the trajectories of health care workers in an operating room[C]// CHI '06 Extended Abstracts on Human Factors in Computing Systems. ACM, 2006:1091-1096. 